\title{
RISK OF PSYCHOSOCIAL PROBLEMS IN CHILDREN WHOSE PARENTS RECEIVE OUTPATIENT SUBSTANCE ABUSE TREATMENT
}

\author{
Marina E. Geschiere, Renske Spijkerman, and Anke de Glopper
}

\begin{abstract}
The entrance of parents into substance abuse treatment provides a unique opportunity to discuss parenting with them, and to inquire about the psychological wellbeing of their children. This is important because parental substance abuse is associated with an increased risk for the development of mental health problems in children. In this study, clients from a Dutch outpatient treatment facility who had custody of or regular contact with their children completed the Strengths and Difficulties Questionnaire (SDQ) about their children aged 4 to 17 years $(N=99)$, after being referred to a parenting consultation with a specialized professional. Compared to other studies conducted in Western Europe and Australia with similar at-risk populations, the SDQ results in the present study suggested a lower percentage of children with psychosocial problem behavior. Still, $29 \%$ of the children in our sample showed psychosocial problems in the clinical range. According to logistic regression analyses, which tested associations between client and family characteristics and risk of psychosocial problems, 5 factors (client's gender, education level, presence of financial debts, child's age, and absence of siblings) were associated with a higher likelihood of one or more types of psychosocial problems. Present findings suggest that, of children whose substance-abusing parents enter outpatient treatment, almost one third may have psychosocial problems that require further assessment and treatment.
\end{abstract}

Keywords: substance abuse treatment, mental health, children of substance abusers, psychosocial problems, Strengths and Difficulties Questionnaire

Acknowledgement: This research did not receive any specific grant from funding agencies in the public, commercial, or not-for-profit sectors.

Marina Geschiere MSc (the corresponding author) is a clinical child psychologist at Parnassia Group (Brijder Addiction Care), The Netherlands. The correspondence address is: Marina Geschiere, Johanna Westerdijkplein 1, 2521 EN Den Haag, The Netherlands. Email: m.geschiere@parnassiagroep.nl

Renske Spijkerman $\mathrm{PhD}$ is a senior researcher at Parnassia Addiction Research Center, Parnassia Group (Brijder Addiction Care), Zoutkeetsingel 40, 2512 HN The Hague, The Netherlands. Email: r.spijkerman@brijder.nl

Anke de Glopper MSc is a junior researcher at Parnassia Addiction Research Center, Parnassia Group (Brijder Addiction Care), Zoutkeetsingel 40, 2512 HN The Hague, The Netherlands. Email: a.deglopper@brijder.nl 
Parental drug use is associated with several emotional, behavioral, social, academic, and physical problems among children throughout their life course (Clark, Cornelius, Wood, \& Vanyukov, 2004; Ranta \& Raitasalo, 2015; van den Einde-Bus, Goldschmeding, Tielen, de Waart, \& van de Looij-Jansen, 2010. Maternal drug use during pregnancy can cause premature birth, slowed growth (Vucinovic et al., 2008) and low birthweight (Schuetze \& Eiden, 2006; Behnke et al., 2013). In their childhood years, children of substance-abusing parents (CSAP) are at increased risk for developing anxiety problems (Diaz et al., 2008; Hill, Tessner, \& McDermott, 2011), hyperactivity (Marmorstein, Iacono, \& McGue, 2009; Sayal et al., 2009), aggressive behavior (Molina, Donovan, \& Belendiuk, 2010), and reduced intellectual abilities (Bennett, Bendersky, \& Lewis, 2008; Yang \& Kramer, 2012). As adolescents, CSAP are more prone to develop mental disorders compared to their peers without substance-abusing parents (Diaz et al., 2008; Elkins, Fite, Moore, Lochman, \& Wells, 2014; Hill et al., 2011; Kelley \& Fals-Stewart, 2004). Despite these increased developmental risks, not all children with a substance-abusing parent or parents experience developmental problems or other negative outcomes. As described by Hosman, van Doesum, and van Santvoort (2009), the intergenerational transmission of psychopathology to CSAP depends on a complex interplay between risk and protective factors in the child's environment, the parent's environment, the social environment, and the wider community. For the development of effective preventive interventions, it is important to learn more about which CSAP are most at risk for developing negative outcomes and how to support these children at an early stage.

Problems that CSAP may experience often go undetected or are recognized at a relatively late stage. Early signs of problematic behavior in CSAP are easily missed when parents are unaware of the symptoms and risks of developmental problems in their children (Shahrbabaki et al., 2010). Furthermore, substance abuse may negatively affect parental sensitivity and monitoring, resulting in less reliable or late problem recognition (Elkins, McGue, Malone, \& Iacono, 2004; Robertson, Baird-Thomas, \& Stein, 2008). In addition, societal stigmatization of substance-abusing parents can be a hampering factor for these parents when it comes to seeking help and being open with professionals about their personal and family problems (Stringer \& Baker, 2015). Fear that openness might lead to negative consequences, such as losing custody of their children, increases parents' reluctance to seek or accept help. We therefore suggest that easily accessible parenting support and empowerment of substance-abusing parents in their parenting role may increase early detection of and intervention in developmental problems in CSAP.

Since psychosocial problems in CSAP can evolve during their life course, it is important to monitor children's mental health status on multiple occasions. The decision of parents to enter treatment provides counselors with a unique opportunity to inquire about parenting and the wellbeing of their client's children, and to lend additional support as required. For many parents with substance abuse problems, being or becoming a parent can motivate them to seek treatment and change their harmful behavior (Fulcher, 2009; Jessup, Humphreys, Brindis, \& Lee, 2003). Parental recovery from substance abuse is likely to contribute to a better living environment for CSAP. Conversely, improvements in the living environment and wellbeing of CSAP can positively affect recovery of parents in treatment (Lander, Howsare, \& 
Byrne, 2013). Due to this interplay, paying attention to parenthood and parenting issues during treatment may not only contribute to parents' recovery from substance abuse but may also prevent mental health disorders in a new generation (Niccols et al., 2012).

For workers in adult mental health treatment organizations, assessing and addressing the needs of their client's children is still considered complex and challenging (Lauritzen, Reedtz, van Doesum, \& Martinussen, 2014; Marsh, Smith, \& Bruni, 2011). Possible explanations for the perceived difficulties associated with routine assessments of parenthood and CSAP in adult treatment may be that workers are often preoccupied with the mental health problems of the parent, or that they fear discussing parenting might interrupt the client-worker relationship. With regard to family-related issues, professionals may feel they have insufficient time or skills to conduct adequate assessments (Gruenert, Ratnam, \& Tsantefski, 2006). Aside from this, clients can fear the involvement of Child Protective Services when they open up about their parenting (Lander et al., 2013).

Possibly due to the above-mentioned difficulties with implementing routine assessments of client's children and family situations, collection of data on the mental health of CSAP at the point when their parents receive treatment has been limited (Niccols et al., 2012; Oliveros \& Kaufman, 2007; Reedtz, Lauritzen, \& Van Doesum, 2012). More research on this subject is needed for two reasons. First, data gathered from children whose parents enter addiction treatment could provide additional insights about the strengths and needs of children of substance-abusing parents. Second, more specific data about the prevalence of internalizing and externalizing problem behavior in children of parents in substance abuse treatment, and about the features that function as mediators between the problems of the parent and the wellbeing of their offspring, are important for the development of interventions to support substance-abusing parents and their children.

Few studies have reported on the wellbeing of CSAP during their parents' treatment trajectories. Some studies reported elevated rates of mental health problems in these children, such as the study by VanDeMark et al. (2005), which assessed 253 children (5-10 years) of mothers who entered treatment for substance abuse, domestic violence, and trauma problems. Of these children, $40 \%$ showed signs of internalizing problem behavior and 37\% showed signs of externalizing problem behavior. Another example is provided by Gruenert et al. (2006), who assessed the psychosocial wellbeing of 48 CSAP using the parent version of the Strengths and Difficulties Questionnaire (SDQ; Goodman, 1997) during parents' participation in substance abuse treatment and a family intervention. Results showed significantly higher levels of emotional symptoms, conduct problems, hyperactivity, and peer problems in CSAP when compared to a general population sample. Burstein, Stanger, Kamon, \& Dumenci's (2006) study of 399 children of 251 parents during substance abuse treatment correlated Child Behavior Checklist (CBCL) scores to parenting practices and found that negative parenting (less positive involvement, negative or ineffective discipline, and less monitoring) was significantly correlatedwith externalizing behavior in this group of CSAP. Burns, Solis, Shadur, \& Hussong (2013) investigated the psychiatric wellbeing of children $(n=81)$ whose parents were in different types of substance abuse treatment. According to their findings, children of parents in medication/detoxification treatment showed higher levels of 
somatization, social withdrawal, and attention problems compared to children whose parents received outpatient treatment. However, for other forms of problematic behavior such as hyperactivity, aggression, anxiety, and depression, no differences across treatment types (medication/detoxification, outpatient, and inpatient) were found.

Two other studies conducted during parental treatment did not find more mental health problems in CSAP than in peers without substance-abusing parents. For example, Redelinghuys and Dar (2008) found no abnormalities in SDQ subscores and total scores for the mental health of children $(n=152)$ as reported by their parents who had been admitted to a detoxification unit. Another study, conducted by Conners et al. (2003) with 4,084 children of mothers in residential substance abuse treatment, concluded that even though a quarter of the children showed problem behavior at school, and had certain physical difficulties (such as asthma, hearing, and vision problems) at a greater rate than the controls, they did not experience more mental health problems than their peers in a community sample.

Since the wellbeing of CSAP is seen as a result of the interplay among risk factors on different levels (Hosman et al., 2009), many studies have investigated child, family, and environment features as potentially influencing factors of psychopathology in CSAP (Luthar \& Cushing, 1999; Steinhausen, Dal Mas, Ledermann, \& Metzke, 2006; Vitaro, Wanner, Brendgen, \& Tremblay, 2008). Ineffective parenting, and, in particular, harsh parenting (Robertson et al., 2008; Conners-Burrow et al., 2013) and lack of parental monitoring (Molina et al., 2010) are seen as important predictors of negative outcomes in the child (Burlew et al., 2013; McMahon, Winkel, \& Rounsaville, 2008; Vitaro et al., 2008). Also, both comorbid mental disorders (Hussong, Flora, Curran, Chassin, \& Zucker, 2008; Peleg-Oren \& Teichman, 2006) and the number of other family members with substance abuse problems are often related to psychopathology in CSAP (Diaz et al., 2008; Molina et al., 2010; Hill et al., 2011). Certain neighborhood features are important at the environmental level. These include neighborhood residential instability (Buu et al., 2009) and neighborhood quality as defined by income; frequency of moving; and rates of public assistance, unemployment, single-parent households, residents under 18 years, and vacant houses (Ridenour et al., 2009). Populations in the abovementioned studies did not all specifically consist of CSAP whose parents received substance abuse treatment. Therefore, less is known about which child-related, parental, and environmental factors are linked to the type and severity of psychosocial problem behavior in CSAP at the time that their parents are receiving treatment. This lack of a specific focus on CSAP during parental treatment suggests that more research concerning the variability in the risk of developing mental health problems could be helpful for the further development of suitable interventions for this group of vulnerable children.

The present study aimed to provide more insight into the prevalence of parent-rated psychosocial problems and related characteristics among CSAP at the time their parents received outpatient substance abuse treatment. The SDQ was used to screen the CSAP's psychosocial wellbeing as this commonly used instrument is regarded as short, user-friendly, and valid. Due to the increased risk of CSAP developing mental health problems, we expected that the children in our study were more likely to show a clinical score for internalizing and externalizing problem behavior in comparison to children from community samples. In 
addition to demographic information about gender, age, nationality, and education level, the parents’ substance use, employment, and financial situation were taken into account.

In line with Hosman and colleagues (2009) and findings from other studies (Hussong et al., 2008; Sayal et al., 2009; Burns et al., 2013) suggesting that the actual development of problematic behavior of the child often depends on the number and severity of detrimental characteristics at the child, parent, and/or environmental level, we expected to find more problems regarding the mental health of CSAP in families with lower levels of education of the parents, parental poly-drug use, unemployment, and financial problems.

\section{Methods}

\section{Study Sample and Setting}

Our study is based on data routinely collected for treatment purposes from 99 parents who received outpatient treatment at Brijder addiction care, a large addiction care organization in the western part of the Netherlands. According to the new treatment policy of this facility, in line with the upcoming Dutch legislation on the Mandatory Reporting Code for Domestic Violence and Child Abuse (Ministry of Health, Welfare and Sport, 2013) ${ }^{1}$, all clients entering the outpatient treatment departments who either had custody of children between 0 and 18 years old or had contact (weekly or biweekly) with their children were invited for at least one consultation with a social worker trained and specialized in providing parenting support to clients with substance use disorders. During this consultation, the children's wellbeing and the client's own parenting-related experiences, questions, and demands were discussed. In addition, as part of a standardized procedure, the specialized professional noted basic client characteristics and asked clients with children in the appropriate age range (4 to 17 years) to complete the SDQ. ${ }^{2}$ Prior to the administration of the SDQ, clients received oral and written information about the study and were invited to participate. All clients provided written informed consent. Data were anonymously coded, analyzed, and stored in a separate digitally protected file that could only be accessed by the involved researchers via the secure digital environment of the treatment facility.

\section{Assessments}

To examine whether children of parents entering our addiction care facility might suffer from psychosocial problems, the Parent version of the SDQ was used. This is a commonly applied screening instrument for detecting psychosocial problems in youth and is suitable for 4- to 17-year-olds (Goodman, 1997). A deviating score on the SDQ might indicate the presence of psychosocial problems and warrants further examination. The parent and self-report version

\footnotetext{
${ }^{1}$ The new law obliges organizations and independent professionals to adhere to a reporting code targeting domestic violence and child abuse. As well as the standard protocol, professionals and organizations that work with adult clients are encouraged to use the "Child Check". This short procedure should be performed during contact with adult clients and involves checking whether they have children and whether these children may be at risk.

${ }^{2}$ Deviating scores on the SDQ and other signals that might indicate problems among CSAP were discussed in a multidisciplinary team under the supervision of a child psychiatrist. Based on this discussion, advice was formulated about additional support for the child and family. Both the SDQ-outcomes and the formulated advice were shared with the client and his or her family during a follow-up meeting with a specialized social worker. Specific support on family- and parenting-related issues during addiction treatment and recovery for the client was provided by the addiction treatment facility. In case additional support was needed for the client's children or family, referrals were made to child mental health care organizations and specialized family treatment.
} 
of the SDQ have been validated in the Netherlands (Muris, Meesters, \& Van Den Berg, 2003; van Widenfelt, Goedhart, Treffers, \& Goodman, 2003).

The first part of the questionnaire consists of 25 items containing three answer categories: 0 = not true, 1 = somewhat true, 2 = certainly true. The items comprise five different subscales with five items each. Each scale is calculated by using the sum of the corresponding items, resulting in scales for emotional symptoms $(\alpha=.72)$, conduct problems $(\alpha=.65)$, hyperactivity/inattention ( $\alpha=.82)$, peer relationship problems $(\alpha=.56)$, and prosocial behavior $(\alpha=.72)$. A Total Difficulties Score (TDS) can be calculated from the first four subscales that measure difficulties ( $\alpha=.85$ ); the prosocial scale measures strengths and therefore has been excluded from the calculation. We dichotomized the scores of the TDS and the four subscales according to cut-off points that are used in Dutch populations (Crone, Vogels, Hoekstra, Treffers, \& Reijneveld, 2008; Stone et al., 2015; van Santvoort, Hosman, van Doesum, \& Janssens, 2013). For the TDS, a score of 14 and above indicated that problems were in the clinical range. A cut-off score of 3 or higher was used for peer and conduct problems. For emotional problems, lack of prosocial behavior, and hyperactivity/inattention we used the cutoff scores of 4, 5, and 6 respectively.

Background information about the participants was gathered on the following characteristics: age, gender, education level, employment status, presence of financial debts, number of children, type of substance disorder, and presence of other mental disorders. For the child, age and gender were recorded.

\section{Analyses}

For the analyses, the data of only one child per client were used. If a parent had filled out the SDQ for two or more children, we randomly selected one child and entered his or her SDQ outcomes in the analyses. This way we were able to focus on the specific relationship between client characteristics and the risk of psychosocial problems of the clients' child. Possible mutual influences of siblings and other family members were not taken into account due to the large variability in types of family relations (biological, non-biological, half- and step-siblings) and numbers of involved family members (biological father or mother, grandparents, foster parents, partners, ex-partners, and other family members), and the fact that information about the child was only reported by the substance-abusing parent who had entered our treatment facility.

To examine which factors were associated with a higher likelihood of psychosocial problems in CSAP, we developed explanatory models based on the existing empirically established and potentially influencing factors and tested the predictive value of these explanatory models by means of binary logistic regression analyses. As dependent variables we included the dichotomous outcomes of the SDQ for the TDS and the five subscales.

Independent variables considered for the explanatory models were all of the client characteristics presented in Table 1 . Age of client and child and type of substance use disorder were categorized into: client's age $(0=26-39,1=\geq 40)$, child's age $(0=4-6,1=7-11,2=$ 12-17), and type of substance disorder ( $0=$ alcohol, $1=$ other substances). 
Before conducting further analyses, we checked the expected cell counts for each combination of independent and dependent variables by conducting cross-tables and chisquared tests. Logistic regression analyses were only performed on dependent variables that met the expected cell counts. According to diagnostics for multicollinearity, none of the independent variables showed a tolerance less than 10 or a variance inflation factor greater than 10. To examine which factors were associated with the outcomes for the TDS and each subscale of the SDQ, we followed the procedure for logistic regression models suggested by Hosmer and Lemeshow (2000). In the first step of the analytic procedure, bivariate logistic regression analyses for each predictor with the dependent variable were performed to determine which predictors were allowed in further multivariate analyses. Only variables showing associations with the dependent variable at a level of $p<.25$ were retained. In the second step, logistic regression analyses were performed while entering all variables that were selected on the basis of the first step of the analytic procedure. Following backward selection, predictors with the highest $p$ values were removed until the final models included either significant predictors $(p$ $<.05$ ) or predictors with $p<.10$ that significantly increased the fit and explained the variance of the model. The latter was assessed by inspecting the model fit indices and the change in -2 log likelihood $(p<.05)$ between the model with and without the predictor. Statistical analyses were performed using SPSS version 23.0.

\section{Results}

\section{Sample Characteristics}

Table 1 presents an overview of clients' and their children's characteristics. In total, 99 parents (50.5\% female) who entered the addiction care facility completed the SDQ for at least one of their children. To examine the presence of psychosocial problems in CSAP, we used children's mean scores on the parent-rated SDQ as well as the prevalence of children scoring above the Dutch cut-off values. These results are shown in the lower part of Table 1. 
Table 1 Descriptive Statistics $(N=99)$

\begin{tabular}{|c|c|c|}
\hline Client and child characteristics & $M(S D)$ & $N(\%)$ \\
\hline \multicolumn{3}{|l|}{ Client characteristics } \\
\hline Age in years (26-57 yrs.) & $40.3(7.0)$ & \\
\hline $26-39$ yrs. & & 49 (49.5) \\
\hline $40-57$ yrs. & & $50(50.5)$ \\
\hline Gender: Female & & $50(50.5)$ \\
\hline Nationality: Non-Dutch & & $24(24.2)$ \\
\hline Education: Low (primary or lower vocational education) & & $75(75.8)$ \\
\hline Employment: Unemployed & & $68(68.7)$ \\
\hline Financial situation: Debts & & $56(56.6)$ \\
\hline \multicolumn{3}{|l|}{ Abuse diagnosis: } \\
\hline Alcohol & & $72(72.7)$ \\
\hline Cannabis & & $13(13.1)$ \\
\hline Cocaine & & $7(7.1)$ \\
\hline Gambling & & $2(2.1)$ \\
\hline Opioids & & $2(2.0)$ \\
\hline Amphetamine & & $1(1.0)$ \\
\hline Gaming & & $1(1.0)$ \\
\hline Prescription drugs & & $1(1.0)$ \\
\hline Other mental disorder(s) according to DSM-IV-TR criteria & & $58(58.6)$ \\
\hline \multicolumn{3}{|l|}{ Child characteristics } \\
\hline Child’s age (4-17 yrs.) & $9.4(3.4)$ & \\
\hline $4-8$ yrs. & & $28(28.3)$ \\
\hline $8-10$ yrs. & & $33(33.3)$ \\
\hline $11-17$ yrs. & & $38(38.4)$ \\
\hline Child's gender: Girl & & $50(50.5)$ \\
\hline Presence of siblings: Yes & & $44(44.4)$ \\
\hline \multicolumn{3}{|l|}{ Parent-reported SDQ-scores } \\
\hline Total Difficulties Score (0-40) & $9.9(6.5)$ & \\
\hline$\%$ clinical cut-off score & & $29(29.3)$ \\
\hline Emotional symptoms (0-10) & $2.5(2.4)$ & \\
\hline \% clinical cut-off score & & $31(31.3)$ \\
\hline Conduct problems (0-10) & $1.8(2.0)$ & \\
\hline \% clinical cut-off score & & $26(26.3)$ \\
\hline Hyperactivity/ inattention (0-10) & $3.9(2.7)$ & \\
\hline \% clinical cut-off score & & $28(28.3)$ \\
\hline Peer relationship problems (0-10) & $1.7(1.7)$ & \\
\hline \% clinical cut-off score & & $28(28.3)$ \\
\hline Prosocial behavior (0-10) & $8.6(1.8)$ & \\
\hline \% clinical cut-off score & & $7(7.1)$ \\
\hline
\end{tabular}




\section{Binary Logistic Regression Analyses}

Probably due to the fact that very few children scored above the cut-off value on the prosocial behavior scale ( $n=7$ ), chi-squared tests indicated that the expected cell counts for this subscale were too low. Therefore, we did not perform logistic regression analyses for the prosocial behavior scale. Outcomes for the TDS and the other subscales of the SDQ are presented in Table 2.

Results of the bivariate logistic regression analyses predicting a clinical score for TDS indicated that 7 out of 13 predictors fulfilled the criterion $(p<.25)$ for entering the multivariate analysis. Two of these predictors were significantly associated $(p<.05)$ with TDS. As shown in Table 2, a clinical TDS was more likely to be found in children of clients with low education levels and in children from clients with financial debts.

According to the findings for emotional symptoms, 6 of the 13 predictors showed a $p$ value $<.25$. None of these predictors were significant at $p<.05$.

Bivariate analyses predicting clinical scores on the conduct problem scale showed that 4 of the 13 predictors had a $p$-value $<.25$. Two of these predictors were significant at $p<.05$ suggesting that elevated scores on the conduct problem scale were more likely to be found in children from clients with low education levels and in children without siblings compared to children from clients with high education levels and children with siblings.

For hyperactivity/inattention, we found that 4 of the 13 predictors showed associations with $p<.25$. Only 1 of these 4 predictors was significant at $p<.05$ indicating that children with clinical scores for hyperactivity/inattention were more likely to be reported by female than by male clients.

Finally, bivariate logistic regression analyses predicting peer relationship problems indicated that 5 of the 13 predictors had $p<.25$. One of these 5 predictors showed a significant association $(p<.05)$ with peer relationship problems, suggesting that children with a clinical score for peer relationship problems were more likely to be found among clients with low education levels than among clients with high education levels. 
Table 2 Prevalence of Clinical Scores on SDQ-subscales by Client Characteristics

\begin{tabular}{|c|c|c|c|c|c|c|c|c|c|c|c|}
\hline \multirow[b]{2}{*}{ Characteristics } & & \multicolumn{2}{|c|}{$\begin{array}{c}\text { Total } \\
\text { Difficulties } \\
\end{array}$} & \multicolumn{2}{|c|}{$\begin{array}{l}\text { Emotional } \\
\text { Symptoms } \\
\end{array}$} & \multicolumn{2}{|c|}{$\begin{array}{c}\text { Conduct } \\
\text { Problems } \\
\end{array}$} & \multicolumn{2}{|c|}{$\begin{array}{c}\text { Hyperactivity/ } \\
\text { Inattention } \\
\end{array}$} & \multicolumn{2}{|c|}{$\begin{array}{c}\text { Peer } \\
\text { Problems } \\
\end{array}$} \\
\hline & & $\%$ & $p$ value & $\%$ & $p$ value & $\%$ & $p$ value & $\%$ & $p$ value & $\%$ & $p$ value \\
\hline \multicolumn{12}{|l|}{ Client } \\
\hline \multirow[t]{2}{*}{ Age } & 26-39 & 34.7 & .244 & 36.7 & .251 & 24.5 & .692 & 36.7 & .068 & 32.7 & .341 \\
\hline & $40<$ & 24.0 & & 26.0 & & 28.0 & & 20.0 & & 24.0 & \\
\hline \multirow[t]{2}{*}{ Gender } & Male & 22.4 & .141 & 28.6 & .561 & 22.4 & .395 & 18.4 & .033 & 20.4 & .088 \\
\hline & Female & 36.0 & & 34.0 & & 30.0 & & 38.0 & & 36.0 & \\
\hline \multirow[t]{2}{*}{ Nationality } & Dutch & 32.0 & .300 & 32.0 & .795 & 28.0 & .489 & 29.3 & .682 & 26.7 & .529 \\
\hline & Non-Dutch & 20.8 & & 29.2 & & 20.8 & & 25.0 & & 33.3 & \\
\hline \multirow[t]{2}{*}{ Education level } & High & 12.5 & .048 & 16.7 & .084 & 8.3 & .035 & 25.0 & .682 & 8.3 & .023 \\
\hline & Low & 34.7 & & 36.0 & & 32.0 & & 29.3 & & 34.7 & \\
\hline \multirow[t]{2}{*}{ Employment status } & Yes & 22.6 & .324 & 22.6 & .210 & 19.4 & .295 & 22.6 & .397 & 25.8 & .712 \\
\hline & No & 32.4 & & 35.3 & & 29.4 & & 30.9 & & 29.4 & \\
\hline \multirow[t]{2}{*}{ Financial problems } & No & 16.3 & .015 & 20.9 & .054 & 20.9 & .293 & 18.6 & .065 & 23.3 & .332 \\
\hline & Yes & 39.3 & & 39.3 & & 30.4 & & 35.7 & & 32.1 & \\
\hline \multirow[t]{2}{*}{ Type of Substance } & Alcohol & 26.4 & .302 & 34.7 & .236 & 23.6 & .330 & 26.4 & .495 & 29.2 & .750 \\
\hline & Other & 37.0 & & 22.2 & & 33.3 & & 33.3 & & 25.9 & \\
\hline \multirow[t]{2}{*}{ Other diagnosis } & No & 22.0 & .180 & 22.0 & .095 & 17.1 & .085 & 24.4 & .471 & 19.5 & .107 \\
\hline & Yes & 34.5 & & 37.9 & & 32.8 & & 31.0 & & 34.5 & \\
\hline \multicolumn{12}{|l|}{ Child } \\
\hline \multirow[t]{3}{*}{ Age } & $4-6$ & 25.0 & .170 & 28.6 & .303 & 25.0 & .504 & 28.6 & .384 & 10.7 & .057 \\
\hline & $7-11$ & 21.2 & & 24.2 & & 21.2 & & 18.2 & & 39.4 & \\
\hline & $12-17$ & 51.8 & & 39.5 & & 31.6 & & 36.8 & & 31.6 & \\
\hline \multirow[t]{2}{*}{ Gender } & Male & 32.0 & .550 & 38.0 & .150 & 30.0 & .395 & 32.0 & .408 & 30.0 & .702 \\
\hline & Female & 26.5 & & 24.5 & & 22.4 & & 24.5 & & 26.5 & \\
\hline Presence of & No & 34.5 & .202 & 32.7 & .735 & 36.4 & .014 & 36.4 & .050 & 36.4 & .050 \\
\hline siblings & Yes & 22.7 & & 29.5 & & 13.6 & & 18.2 & & 18.2 & \\
\hline
\end{tabular}

Note. $p<.25$ in bold. 
In the second step of the analytic procedure, we performed separate multivariate backward regression analyses for the TDS and the subscales of the SDQ. In each regression model we included all predictors with $p<.25$ according to previous bivariate analyses. The final regression models are presented in Table 3. As shown, the chi-squared statistics of the five final models were all significant, indicating that they provided a better prediction of the dependent variable (a clinical score on one of the SDQ scales) than the constant-only models.

Table 3 Logistic Regression Analyses Predicting Risk of Psychosocial Problems According to the Parent-rated SDQ

\begin{tabular}{|c|c|c|c|c|c|}
\hline Predictor & OR & $(95 \% \mathrm{CI})$ & $p$ & Model $\chi^{2}$ & $p$ \\
\hline \multicolumn{6}{|l|}{ Total Difficulties } \\
\hline Client's education: Low & 3.75 & $(0.91,15.51)$ & .068 & 15.36 & .004 \\
\hline Financial situation: Debts & 3.39 & $(1.16,9.93)$ & .026 & & \\
\hline Child's age: $12-17$ yrs. (ref) & & & .047 & & \\
\hline 4-6 yrs. & 0.28 & $(0.09,0.94)$ & .039 & & \\
\hline 7-11 yrs. & 0.28 & $(0.09,0.90)$ & .034 & & \\
\hline \multicolumn{6}{|l|}{ Emotional Symptoms } \\
\hline Financial situation: Debts & 2.44 & $(0.98,6.07)$ & .054 & 3.91 & .048 \\
\hline \multicolumn{6}{|l|}{ Conduct Problems } \\
\hline Presence of siblings: Yes & 0.34 & $(0.12,0.96)$ & .041 & 10.74 & .005 \\
\hline Client's education: Low & 4.00 & $(0.84,19.01)$ & .081 & & \\
\hline \multicolumn{6}{|l|}{ Hyperactivity/Inattention } \\
\hline Client's gender: Female & 2.99 & $(1.16,7.74)$ & .023 & 9.07 & .010 \\
\hline Financial situation: Debts & 2.71 & $(1.02,7.18)$ & .045 & & \\
\hline \multicolumn{6}{|l|}{ Peer Problems } \\
\hline Client's education: Low & 7.04 & $(1.48,33.45)$ & .014 & 15.78 & .001 \\
\hline Child's age: 4-6 yrs. (ref) & & & .038 & & \\
\hline 7-11 yrs. & 5.85 & $(1.43,23.99)$ & .014 & & \\
\hline 12-17yrs. & 5.22 & $(1.26,21.66)$ & .023 & & \\
\hline
\end{tabular}

The final regression model predicting the likelihood of a clinical score on the TDS included three remaining factors: client's education level, financial problems, and child's age. Although client's education level was not significant at the .05 level, it did show a marginally significant association $(p=.068)$ and contributed to a better model fit (change in -2 log likelihood $=3.876, p<.05$ ). We therefore kept this factor in the final model. Significant associations for financial debts and child's age group suggest that a clinical score on the TDS was more likely to be found in children of clients with financial debts compared to children of clients without financial debts (OR = 3.39, 95\% CI: 1.16, 9.93), and in children aged 12 to 17 years compared to children from the age groups 4 to 6 years (OR $=0.28,95 \% \mathrm{CI}: 0.09,0.94$ ) 
and 7 to 11 years $(\mathrm{OR}=0.28,95 \% \mathrm{CI}$ : 0.09, 0.90). The marginal association for client's education level could suggest that children of clients with low education levels are more likely to show a clinical score on the TDS than children of clients with high education levels (OR = 3.75, 95\% CI: 0.91, 15.51).

Multivariate logistic regression analyses predicting the likelihood of a clinical score on the subscale for emotional symptoms resulted in a final model with only one remaining predictor: financial problems. The association between the predictor and emotional symptoms was, however, marginally significant $(p=.054)$, suggesting that children of clients with financial debts might be more likely to show emotional symptoms (OR $=2.44$, 95\% CI: 0.98, 6.07).

The final model predicting the likelihood of a clinical score for conduct problems included two predictors: presence of siblings, and client's education level. Although the association for client's education level was only a marginally significant trend $(p=.081)$, it contributed significantly to the fit of the explanatory model (change in -2 log likelihood = $3.891, p<.05$ ). According to our findings, a clinical score for conduct problems was less likely to be found in children with siblings than in children without siblings (OR $=0.34,95 \% \mathrm{CI}$ : 0.12, 0.96). The marginal trend for client's education level could indicate that children of clients with low education levels are more likely to show a clinical score for conduct problems than children of clients with high education levels (OR $=4.00,95 \% \mathrm{CI}: 0.84,19.01$ ).

A clinical score for hyperactivity/inattention was predicted by two client factors: gender and financial situation. Associations for both factors were significant indicating that children with a clinical score for hyperactivity/inattention were more likely to be reported by female than by male clients (OR $=2.99,95 \% \mathrm{CI}: 1.16,7.74)$ and by clients with financial debts than by those without debts (OR $=2.71,95 \% \mathrm{CI}: 1.02,7.18)$.

Finally, results for peer relationship problems showed significant associations for client's education level and child's age. These findings suggest that peer relationship problems were more likely to be found in children of clients with low education levels compared to children of clients with higher education levels (OR = 7.04, 95\% CI: 1.48, 33.45). In addition, both 7- to 11-year-olds (OR $=5.85,95 \% \mathrm{CI}$ : $1.43,23.99)$ and 12 - to 17 -year-olds (OR $=5.22$, 95\% CI: 1.26, 21.66) were more likely to show clinical scores for peer relationship problems than were 4- to 6-year-olds.

\section{Discussion}

This study aimed to provide more insight into psychosocial problems of CSAP whose parents were receiving substance abuse treatment. According to our findings, 29\% were classified by the Strengths and Difficulties Questionnaire (SDQ) as having psychosocial problems in the clinical range. In line with the literature (Hosman et al., 2009), our sample showed higher SDQ scores than Dutch children from general populations (Bot, de Leeuw den Bouter, \& Adriaanse, 2011; Crone et al., 2008; Mieloo et al., 2012; Muris et al., 2003; van Widenfelt et al., 2003; Vogels, Crone, Hoekstra, \& Reijneveld, 2009). However, lower SDQ scores were observed in our study than in previous studies concerning Dutch children from at- 
risk populations (Kaptein, Jansen, Vogels, \& Reijneveld, 2008; van der Zanden, Speetjens, Arntz, \& Onrust, 2010; van Santvoort, Hosman, van Doesum, \& Janssens, 2014; Wansink, Janssens, Hoencamp, Middelkoop, \& Hosman, 2015). Furthermore, studies that used the SDQ to address psychosocial problems in CSAP showed comparable (Dawe \& Harnett, 2007; Comiskey, Milness, \& Daly, 2017) or somewhat lower (Gruenert et al., 2006; Redelinghuys \& Dar, 2008) mean scores than those reported in children of parents with predominantly nonsubstance-related mental disorders (van Santvoort et al., 2013; van der Zanden et al., 2010; Wansink et al., 2015). Still, the SDQ scores in the present study were the lowest.

The remarkably lower rates of psychosocial problems in our sample might be explained in several ways. First, children's psychosocial problems were reported by the parent who was in treatment for a substance use disorder. In our study, $50 \%$ of the clients were fathers. Since mothers are more often the primary caregivers and may be more likely to observe problematic behavior of their children, such behavior may have been underreported in our data. Similarly, our study population included parents who did not have full custody of their children; this might be associated with having less contact with their children and therefore having an incomplete view of their children's behavior.

Second, the lower rates of psychosocial problems could also be due to differences in sample characteristics between our study and previous research in comparable risk groups. For example, some studies included children who participated in support groups (van Santvoort et al., 2014; van der Zanden et al., 2010) or whose families received additional parenting support (Dawe \& Harnett, 2007; Wansink et al., 2015). Perhaps these children were receiving support because they had already shown signs of problem behavior. The lower rates of parent-reported psychosocial problems in our study could also reflect actual problem rates in CSAP, suggesting that children of substance-abusing parents might experience fewer psychosocial problems than do children from other clinical samples.

A third explanation may be found in certain characteristics of addicted parents themselves that distinguish them from parents with other mental illnesses. Addicted parents may be less likely to perceive problematic behavior in their children. On the other hand, they may be more likely to underreport problems, whether to avoid possible consequences (e.g., involvement of child protection services, losing custody), or because of feelings of guilt or shame. However, as far as we know, differences in parent-reported SDQ scores between substance-abusing parents and parents with other mental disorders have not been addressed in earlier research. The available Dutch studies on the SDQ in at-risk populations were mainly conducted among children whose parents suffered from non-substance-related disorders such as depression and anxiety and only included a small proportion of CSAP (van Santvoort et al., 2014; van der Zanden et al., 2010; Wansink et al., 2015).

In sum, present findings suggest relatively low levels of psychosocial problems in CSAP compared to children from other at-risk populations. However, this finding needs to be replicated in future research before it can serve as a basis for further conclusions. 
Our study findings further showed that an increased risk of psychosocial problems in CSAP was associated with five characteristics: client's financial problems, client's education level, client's gender, child's age, and the presence of siblings. First, children whose parents had financial debts were more likely to show psychosocial problems in general, symptoms of emotional problems, and hyperactivity/inattention. Few studies have investigated financial debts as a predictor of mental health in CSAP. However, a similar link has been found for children whose mothers suffered from depression (Goodman et al., 2004). It is conceivable that financial problems provoke parental stress and conflict (Puff \& Renk, 2014), which could negatively influence parenting and child development (Conger, Conger, \& Martin, 2010). Parents with financial problems might also be reluctant to seek help for their children because of other priorities and expected financial costs, resulting in potential deterioration of their children’s problem behavior (Santiago, Kaltman, \& Miranda, 2013).

A second factor related to a clinical score on the SDQ in the present study was client's education level. Children whose parents had low education levels were more likely to show peer relationship problems than children of parents with higher educational levels. Previous research on children's wellbeing and their parents' socioeconomic status (SES) suggests a similarly negative association, implying that mental health problems are more prevalent in children from families with a low SES than in children from higher socioeconomic backgrounds (Piotrowska, Stride, Croft, \& Rowe, 2015; Rajmil, Herdman, Ravens-Sieberer, Erhart, \& Alonso, 2014; Reiss, 2013). Several studies among children and adolescents from general population samples report similar negative associations between parental education and peer relationship problems (Havas, Bosma, Spreeuwenberg, \& Feron, 2009; de Laat, Essink-Bot, van Wassenaer-Leemhuis, \& Vrijkotte, 2016; Rajmil et al., 2014). A few studies that applied other types of mental health assessments, rather than the SDQ, confirmed that mental health problems were more prevalent in CSAP with low SES, compared to CSAP with higher SES (Ornoy, Segal, Bar-Hamburger, \& Greenbaum, 2001); likewise, mental health problems were more prevalent in CSAP whose mothers had lower educational levels compared to those whose mothers had higher educational levels (Ranta \& Raitasalo, 2015). Economically disadvantaged families often show higher rates of marital problems, parental conflict, and domestic violence (Conger et al., 2010); such factors could mediate the relationship between educational level of the parent and peer relationship problems. Narayan, Sapienza, Monn, Lingras, and Masten (2015), in a sample of homeless, impoverished families, confirmed that domestic violence was related to peer relationship problems, mediated by the extent of parental warmth and of parental criticism and negativity.

Third, according to our findings, client's gender was also associated with a clinical score on one of the subscales of the SDQ. More specifically, we found that mothers were more likely than fathers to report a clinical score for hyperactivity/inattention. This result is in line with a meta-analysis suggesting that mothers report slightly more problem behavior in their children than fathers do (Duhig, Renk, Epstein, \& Phares, 2000), and with previous research among children from clinical samples showing higher levels of attention deficit hyperactivity disorder (ADHD) symptoms reported by mothers than by fathers (Caye, Machado, \& Rohde, 2013; Sollie, Larsson, \& Mørch, 2012). In all of the above-mentioned studies, ADHD 
symptoms were assessed with other instruments than the SDQ. In contrast, two studies addressing differences in parent-reported SDQ scores for hyperactivity/inattention in children from a community sample indicate an association in the opposite direction, with higher levels of ADHD symptoms reported by fathers than by mothers (Chiorri, Hall, Casely-Hayford, \& Malmberg, 2016; Davé, Nazareth, Senior, \& Sherr, 2008). It is not clear yet how these mixed findings should be interpreted, since multiple factors affect how parents perceive, interpret, and report their children's behavior (De Los Reyes \& Kazdin, 2005). A plausible explanation for our finding could be that mothers, since they are most often the primary caregivers, were more likely to notice hyperactivity/inattention problems in their children. Another related explanation is that children of female clients, when living with their mothers, may be more strongly affected by their maternal substance abuse and as a result could be more at risk for developing ADHD (Ornoy et al., 2001). More research is needed, however, to confirm the association between client's gender and ADHD symptoms and to test the proposed explanations.

Fourth, our results showed associations between child age and clinical scores for total difficulties and peer relationship problems. Compared to children in the two younger age groups (4 to 6 years \& 7 to 11 years), children aged 12 to 17 years were more likely to show a clinical score for psychosocial problems in general. For peer relationship problems, 7- to 17year-olds were more likely to show a clinical score than 4- to 6-year-olds.

One explanation might be that these age effects reflect normative developmental differences in psychosocial problems during childhood and adolescence. According to a large international dataset based on assessments with the CBCL among 27,861 adolescents (11 to 18 years) from 25 countries, higher levels of psychosocial problems were found in older (15 to 18 years) compared to younger adolescents (11 to 14 years; Rescorla et al., 2013). Bourdon, Goodman, Rae, Simpson, and Koretz (2005) also propose that psychosocial problems may develop according to different trajectories for boys and girls. In their cross-sectional study among a representative sample of children and adolescents in the United States, parent-reported SDQ scores for boys were higher for ages 8 to 14 years, while for girls SDQ scores were higher for ages 11 to 17 years.

Another explanation can be found in the complex interplay between the reciprocal and cascading effects of different types of psychosocial problems that children may develop over time. It has been suggested that CSAP show higher rates of behavioral problems at a younger age than their peers from community samples (Clark et al., 2004; Molina et al., 2010). These problems could contribute to the development of peer relationship difficulties at a later age, as described by van Lier and Koot (2010), who confirmed similar cascading effects in a community sample of school-aged children. The peer relationship problems, rooted in externalizing problem behavior, were, over time, related to the continuation of externalizing and the onset of internalizing problems. Similar results were found in a sample of children from low-income families (Hoglund \& Chisholm, 2014).

It is important to note that in contrast to the above-mentioned findings from large representative population samples, two studies among at-risk populations did not demonstrate 
any age effects (Hser, Evans, Li, Metchik-Gaddis, \& Messina, 2013; Janssens \& Deboutte, 2010). Furthermore, we found one Dutch study that showed an opposite age effect, indicating that parent-related behavioral and emotional problems may be particularly higher in younger instead of older age groups (Brugman, Reijneveld, Verhulst, \& Verloove-Vanhorick, 2001). Since empirical findings on possible age differences in psychosocial problems remain inconclusive, further research is needed.

The last factor associated with a clinical score on one of the subscales of the SDQ was the presence of siblings. In our study, CSAP with siblings were less likely to show behavior problems than their counterparts without siblings. According to the literature, sibling influences can be protective as well as harmful to a child's development (Kim, McHale, Crouter, \& Osgood, 2007). Within the context of growing up with a substance-abusing parent, which can generate a lot of family stress (Vanderplasschen, Autrique, \& De Wilde, 2010), children with siblings might benefit from mutual support and understanding (Branje, van Lieshout, van Aken, \& Haselager, 2004). In addition, a sibling might take care of a younger child when the parent is not able to. Hence, having siblings can be a protective factor against the development of psychosocial problems in CSAP. On the other hand, siblings may have a negative impact on their brother's or sister's adjustment by serving as negative role models, performing negative, coercive behaviors, and reinforcing mutual problem behavior (Brody et al., 2003; Bullock \& Dishion, 2002).

\section{Limitations}

Finally, before drawing further conclusions, several study limitations need to be mentioned. Due to the cross-sectional design, our data do not allow causal interpretations. Prospective studies are needed to investigate which client and child factors predict further development of psychosocial problems in CSAP during and after their parents' substance abuse treatment. Longitudinal assessments can provide valuable information about the predictors and timing of problem development in CSAP that can be used for treatment and prevention purposes.

Another study limitation involves the absence of multi-informant data. As described earlier, present results are based on parent-reported SDQ outcomes from clients in substance abuse treatment and could contain bias. By using multi-informant data, a better indication of psychosocial problems in CSAP can be obtained. This issue might be particularly relevant when assessing psychosocial problems in CSAP, since these children are more likely to come from "broken” families, and are more often raised by people other than their biological parents.

Another restriction of our study is that we did not measure psychosocial problems in all children, but randomly selected one child per parent. More data about the wellbeing of the other children is important since siblings might be differently affected by their parent's substance abuse.

Although domestic and intimate partner violence are seen as important mediators between parental substance abuse and the wellbeing of the child (Conners-Burrow et al., 2013), we could not include a reliable estimation of the prevalence and extent of domestic violence in 
the study. The data for this study were gathered during the first interview between the social worker and the referred substance-abusing parent. Although workers were experienced in detecting and acting upon signals of child abuse and domestic violence, they did not follow a uniform procedure and the way and the moment that this delicate topic was discussed differed from case to case, depending on the willingness of the parent to speak about their family situation. Some factors that could have affected a parent's willingness to discuss family matters were the amount of distrust with regard to fear of involvement of CPS, the intensity and frequency of contact between parent and child, and comorbid psychological problems of the parent. Since conversations about domestic violence were not systematically and uniformly registered we were not able retrieve a reliable indication for the presence or absence of domestic violence. In future research, more attention should be paid to this important factor.

\section{Conclusion}

The results of this study indicate that $29 \%$ percent of the children whose parents received outpatient substance abuse treatment showed signs of psychosocial problem behavior according to their parents' SDQ reports. Although this percentage is much higher than found for general population samples, it was unexpectedly lower than previously shown by research in children from similar at-risk populations (Dawe \& Harnett, 2007; Gruenert et al., 2006; Redelinghuys \& Dar, 2008; van Santvoort et al., 2014; Wansink et al., 2015). Nevertheless, for almost one third of the children the increased score on the SDQ suggests that further inquiry and possibly additional help is needed. Discussing parenting and the wellbeing of their children with parents who enter substance abuse treatment can contribute to timely referral of CSAP to appropriate help. This emphasizes the need for a more family-oriented approach with special attention paid to children and parenting issues in adult facilities for mental and substance abuse treatment (Gruenert et al., 2006; VanDeMark et al., 2005. 


\section{References}

Behnke, M., Smith, V. C., Levy, S., Ammerman, S. D., Gonzalez, P. K., Ryan, S. A., \& Watterberg, L. (2013). Prenatal substance abuse: Short-and long-term effects on the exposed fetus. Pediatrics, 131, 1009-1024. doi:10.1542/peds.2012-3931

Bennett, D. S., Bendersky, M., \& Lewis, M. (2008). Children’s cognitive ability from 4 to 9 years old as a function of prenatal cocaine exposure, environmental risk, and maternal verbal intelligence. Developmental Psychology, 44, 919-928. doi:10.1037/0012$\underline{1649.44 .4 .919}$

Bot, M., de Leeuw den Bouter, B. J. E., \& Adriaanse, M. C. (2011). Prevalence of psychosocial problems in Dutch children aged 8-12 years and its association with risk factors and quality of life. Epidemiology and Psychiatric Sciences, 20, 357-365. doi:10.1017/S2045796011000540

Bourdon, K. H., Goodman, R., Rae, D. S., Simpson, G., \& Koretz, D. S. (2005). The Strengths and Difficulties Questionnaire: US normative data and psychometric properties. Journal of the American Academy of Child \& Adolescent Psychiatry, 44(6), 557-564. doi:10.1097/01.chi.0000159157.57075.c8

Branje, S. J., van Lieshout, C. F., van Aken, M. A., \& Haselager, G. J. (2004). Perceived support in sibling relationships and adolescent adjustment. Journal of Child Psychology and Psychiatry, 45(8), 1385-1396. doi:10.1111/j.1469-7610.2004.00845.x

Brody, G. H., Ge, X., Kim, S. Y., Murry, V. M., Simons, R. L., Gibbons, F. X., ... \& Conger, R. D. (2003). Neighborhood disadvantage moderates associations of parenting and older sibling problem attitudes and behavior with conduct disorders in African American children. Journal of Consulting and Clinical Psychology, 71(2), 211-222. doi:10.1037/0022-006X.71.2.211

Brugman, E., Reijneveld, S. A., Verhulst, F. C., \& Verloove-Vanhorick, S. P. (2001). Identification and management of psychosocial problems by preventive child health care. Archives of Pediatrics \& Adolescent Medicine, 155(4), 462-469. doi:10.1001/archpedi.155.4.462

Bullock, B. M., \& Dishion, T. J. (2002). Sibling collusion and problem behavior in early adolescence: Toward a process model for family mutuality. Journal of Abnormal Child Psychology, 30(2), 143-153. doi:10.1023/A:1014753232153

Burlew, A. K., Johnson, C., Smith, S., Sanders, A., Hall, R., Lampkin, B., \& Schwaderer, M. (2013). Parenting and problem behaviors in children of substance abusing parents. Child and Adolescent Mental Health, 18(4), 231-239. doi:10.1111/camh.12001 
Burns, A. R., Solis, J. M., Shadur, J. M., \& Hussong, A. M. (2013). Comparing psychiatric symptoms among children of substance-abusing parents with different treatment histories. Vulnerable Children and Youth Studies, 8, 258-271. doi:10.1080/17450128.2012.738948

Burstein, M., Stanger, C., Kamon, J., \& Dumenci, L. (2006). Parent psychopathology, parenting, and child internalizing problems in substance-abusing families. Psychology of Addictive Behaviors, 20(2), 97-106. doi:10.1037/0893-164X.20.2.97

Buu, A., Dipiazza, C., Wang, J., Puttler, L. I., Fitzgerald, H. E., \& Zucker, R. A. (2009). Parent, family, and neighborhood effects on the development of child substance use and other psychopathology from preschool to the start of adulthood. Journal of Studies on Alcohol and Drugs, 70(4), 489-498. doi:10.15288/jsad.2009.70.489

Caye, A., Machado, J. D., \& Rohde, L. A. (2013). Evaluating parental disagreement in ADHD diagnosis: Can we rely on a single report from home? Journal of Attention Disorders. Advance online publication. doi:10.1177/1087054713504134

Chiorri, C., Hall, J., Casely-Hayford, J., \& Malmberg, L. E. (2016). Evaluating measurement invariance between parents using the Strengths and Difficulties Questionnaire (SDQ). Assessment, 23(1), 63-74. doi:10.1177/1073191114568301

Clark, D. B., Cornelius, J., Wood, D. S., \& Vanyukov, M. (2004). Psychopathology risk transmission in children of parents with substance use disorders. American Journal of Psychiatry, 161, 685-691. doi:10.1176/appi.ajp.161.4.685

Comiskey, C. M., Milnes, J., \& Daly, M. (2017). Parents who use drugs: the well-being of parent and child dyads among people receiving harm reduction interventions for opiate use. Journal of Substance Use, 22(2), 206-210. doi:10.1080/14659891.2016.1177616

Conger, R. D., Conger, K. J., \& Martin, M. J. (2010). Socioeconomic status, family processes, and individual development. Journal of Marriage and Family, 2(3), 685-704. doi:10.1111/j.1741-3737.2010.00725.x

Conners, N. A., Bradley, R. H., Mansell, L. W., Liu, J. Y., Roberts, T. J., Burgdorf, K., \& Herrell, J. M. (2003). Children of mothers with serious substance abuse problems: An accumulation of risks. The American Journal of Drug and Alcohol Abuse, 29, 743-758. doi:10.1081/ADA-120026258

Conners-Burrow, N. A., McKelvey, L., Pemberton, J. R., Lagory, J., Mesman, G. R., \& Whiteside-Mansell, L. (2013). Moderators of the relationship between maternal substance abuse symptoms and preschool children's behavioral outcomes. Journal of Child and Family Studies, 22, 1120-1129. 
Crone, M. R., Vogels, A. G., Hoekstra, F., Treffers, P. D., \& Reijneveld, S. A. (2008). A comparison of four scoring methods based on the parent-rated Strengths and Difficulties Questionnaire as used in the Dutch preventive child health care system. BMC Public Health, 8, 106-115. doi:10.1186/1471-2458-8-106

Davé, S., Nazareth, I., Senior, R., \& Sherr, L. (2008). A comparison of father and mother report of child behaviour on the Strengths and Difficulties Questionnaire. Child Psychiatry and Human Development, 39(4), 399-413. doi:10.1007/s10578-008-0097-6

Dawe, S., \& Harnett, P. (2007). Reducing potential for child abuse among methadonemaintained parents: Results from a randomized controlled trial. Journal of Substance Abuse Treatment, 32, 381-390. doi:10.1016/j.jsat.2006.10.003

de Laat, S. A., Essink-Bot, M. L., van Wassenaer-Leemhuis, A. G., \& Vrijkotte, T. G. (2016). Effect of socioeconomic status on psychosocial problems in 5- to 6-year-old pretermand term-born children: The ABCD study. European Child \& Adolescent Psychiatry, 25(7), 757-767. doi:10.1007/s00787-015-0791-4

De Los Reyes, A., \& Kazdin, A. E. (2005). Informant discrepancies in the assessment of childhood psychopathology: a critical review, theoretical framework, and recommendations for further study. Psychological Bulletin, 131(4), 483-509. $\underline{\text { doi:10.1037/0033-2909.131.4.483 }}$

Diaz, R., Gual, A., García, M., Arnau, J., Pascual, F., Cañuelo, B., Rubio, G., ... \& Garbayo, I. (2008). Children of alcoholics in Spain: From risk to pathology. Social Psychiatry and Psychiatric Epidemiology, 43(1), 1-10. doi:10.1007/s00127-007-0264-2

Duhig, A. M., Renk, K., Epstein, M. K., \& Phares, V. (2000). Interparental agreement on internalizing, externalizing, and total behavior problems: A meta-analysis. Clinical Psychology: Science and Practice, 7(4), 435-453. doi:10.1093/clipsy.7.4.435

Elkins, I. J., McGue, M., Malone, S., \& Iacono W. G. (2004). The effect of parental alcohol and drug disorders on adolescent personality. American Journal of Psychiatry, 161, 670-676. doi:10.1176/appi.ajp.161.4.670

Elkins, S. R., Fite, P. J., Moore, T. M., Lochman, J. E., \& Wells, K. C. (2014). Bidirectional effects of parenting and youth substance use during the transition to middle and high school. Psychology of Addictive Behaviors, 28, 475-486. doi:10.1037/a0036824

Fulcher, G. M. (2009). Motherhood and motivation for substance abuse treatment and behavior change. Berkeley, CA: ProQuest.

Goodman, R. (1997). The Strengths and Difficulties Questionnaire: A research note. Journal of Child Psychology and Psychiatry, 38, 581-586. doi:10.1111/j.14697610.1997.tb01545.x 
Goodman, S. H., Rouse, M. H., Connell, A. M., Broth, M. R., Hall, C. M., \& Heyward, D. (2011). Maternal depression and child psychopathology: A meta-analytic review. Clinical Child and Family Psychology Review, 14(1), 1-27. doi:10.1007/s10567-010$\underline{0080-1}$

Gruenert, S. M., Ratnam, S. S., \& Tsantefski, M. (2006). Identifying children's needs when parents access drug treatment: The utility of a brief screening measure. Journal of Social Work Practice in the Addictions, 6, 139-154. doi:10.1300/J160v06n01_07

Havas, J., Bosma, H., Spreeuwenberg, C., \& Feron, F. J. (2009). Mental health problems of Dutch adolescents: The association with adolescents' and their parents' educational level. European Journal of Public Health, 20, 258-264. doi:10.1093/eurpub/ckp172

Hill, S. Y., Tessner, K. D., \& McDermott, M. D. (2011). Psychopathology in offspring from families of alcohol dependent female probands: A prospective study. Journal of Psychiatric Research, 45, 285-294. doi:10.1016/j.jpsychires.2010.08.005

Hoglund, W. L., \& Chisholm, C. A. (2014). Reciprocating risks of peer problems and aggression for children’s internalizing problems. Developmental Psychology, 50(2), 586-599. doi:10.1037/a0033617

Hosman, C. M. H., van Doesum, K. T. M., \& van Santvoort, F. (2009). Prevention of emotional problems and psychiatric risks in children of parents with a mental illness in the Netherlands: I. The scientific basis to a comprehensive approach. Australian eJournal for the Advancement of Mental Health, 8, 250-263. doi:10.5172/jamh.8.3.250

Hosmer, D. W., \& Lemeshow, S. (2000). Applied Logistic Regression (2nd ed.). Hoboken, NJ: John Wiley\& Sons.

Hser, Y. I., Evans, E., Li, L., Metchik-Gaddis, A., \& Messina, N. (2013). Children of treated substance-abusing mothers: A 10-year prospective study. Clinical Child Psychology and Psychiatry, 19(2), 217-232. doi:10.1177/1359104513486999

Hussong, A. M., Flora, D. B., Curran, P. J., Chassin, L. A., \& Zucker, R. A. (2008). Defining risk heterogeneity for internalizing symptoms among children of alcoholic parents. Development and Psychopathology, 20, 165-193. doi:10.1017/S0954579408000084

Janssens, A., \& Deboutte, D. (2010). Psychopathology among children and adolescents in child welfare: A comparison across different types of placement in Flanders, Belgium. Journal of Epidemiology and Community Health, 64(4), 353-359. doi:10.1136/jech.2008.086371

Jessup, M. A., Humphreys, J. C., Brindis, C. D., \& Lee, K. A. (2003). Extrinsic barriers to substance abuse treatment among pregnant drug dependent women. Journal of Drug Issues, 33, 285-304. doi:10.1177/002204260303300202 
Kaptein, S., Jansen, D. E. M. C., Vogels, A. G. C., \& Reijneveld, S. A. (2008). Mental health problems in children with intellectual disability: Use of the Strengths and Difficulties Questionnaire. Journal of Intellectual Disability Research, 52(2), 125-131. doi:10.1111/j.1365-2788.2007.00978.x

Kelley, M. L., \& Fals-Stewart, W. (2004). Psychiatric disorders of children living with drugabusing, alcohol-abusing, and non-substance-abusing fathers. Journal of the American Academy of Child \& Adolescent Psychiatry, 43, 621-628. doi:10.1097/00004583$\underline{200405000-00016}$

Kim, J. Y., McHale, S. M., Crouter, A. C., \& Osgood, D. W. (2007). Longitudinal linkages between sibling relationships and adjustment from middle childhood through adolescence. Developmental Psychology, 43(4), 960-973. doi:10.1037/0012$\underline{1649.43 .4 .960}$

Lander, L., Howsare, J., \& Byrne, M. (2013). The impact of substance use disorders on families and children: From theory to practice. Social Work in Health, 28, 194-205. doi:10.1080/19371918.2013.759005

Lauritzen, C., Reedtz, C., Van Doesum, K. T. M., \& Martinussen, M. (2014). Implementing new routines in adult mental health care to identify and support children of mentally ill parents. BMC Health Services Research, 14, 58. doi:10.1186/1472-6963-14-58

Luthar, S. S., \& Cushing, G. (1999). Neighborhood influences and child development: A prospective study of substance abusers’ offspring. Development and Psychopathology, $11,763-784$.

Marmorstein, N. R., Iacono, W. G., \& McGue, M. (2009). Alcohol and illicit drug dependence among parents: Associations with offspring externalizing disorders. Psychological Medicine, 39, 149-155. doi:10.1017/S0033291708003085

Marsh, J. C., Smith, B. D., \& Bruni, M. (2011). Integrated substance abuse and child welfare services for women: A progress review. Children and Youth Services Review, 33, 466472. doi:10.1016/j.childyouth.2010.06.017

McMahon, T. J., Winkel, J. D., \& Rounsaville, B. J. (2008). Drug abuse and responsible fathering: A comparative study of men enrolled in methadone maintenance treatment. Addiction, 103(2), 269-283. doi:10.1111/j.1360-0443.2007.02075.x

Mieloo, C., Raat, H., van Oort, F., Bevaart, F., Vogel, I., Donker, M., \& Jansen, W. (2012). Validity and reliability of the Strengths and Difficulties Questionnaire in 5-6 year olds: Differences by gender or by parental education? PLOS ONE, 7(5): e36805. doi:10.1371/journal.pone.0036805 
Ministry of Health, Welfare and Sport. (2013). Model reporting code: Domestic violence and child abuse. Retrieved from https://www.government.nl/documents/reports/2013/03/14/model-reporting-codedomestic-violence-and-child-abuse

Molina, B. S., Donovan, J. E., \& Belendiuk, K. A. (2010). Familial loading for alcoholism and offspring behavior: Mediating and moderating influences. Alcoholism: Clinical and Experimental Research, 34, 1972-1984. doi:10.1111/j.1530-0277.2010.01287.x

Muris, P., Meesters, C., \& van den Berg, F. (2003). The Strengths and Difficulties Questionnaire (SDQ). European Child \& Adolescent Psychiatry, 12(1), 1-8. doi:10.1007/s00787-003-0298-2

Narayan, A. J., Sapienza, J. K., Monn, A. R., Lingras, K. A., \& Masten, A. S. (2015). Risk, vulnerability, and protective processes of parental expressed emotion for children's peer relationships in contexts of parental violence. Journal of Clinical Child \& Adolescent Psychology, 44(4), 676-688. doi:10.1080/15374416.2014.881292

Niccols, A., Milligan, K., Sword, W., Thabane, L., Henderson, J., \& Smith, A. (2012). Integrated programs for mothers with substance abuse issues: A systematic review of studies reporting on parenting outcomes. Harm Reduction Journal, 9(1), 1-11. doi:10.1186/1477-7517-9-14

Oliveros, A., \& Kaufman, J. (2011). Addressing substance abuse treatment needs of parents involved with the child welfare system. Child Welfare, 90(1), 25-41.

Ornoy, A., Segal, J., Bar-Hamburger, R., \& Greenbaum, C. (2001). Developmental outcome of school-age children born to mothers with heroin dependency: Importance of environmental factors. Developmental Medicine \& Child Neurology, 43, 668-675. doi:10.1111/j.1469-8749.2001.tb00140.x

Peleg-Oren, N., \& Teichman, M. (2006). Young children of parents with substance use disorders (SUD): A review of the literature and implications for social work practice. Journal of Social Work Practice in the Addictions, 6, 49-61. doi:10.1300/J160v06n01_03

Piotrowska, P. J., Stride, C. B., Croft, S. E., \& Rowe, R. (2015). Socioeconomic status and antisocial behaviour among children and adolescents: A systematic review and metaanalysis. Clinical Psychology Review, 35, 47-55. doi:10.1016/j.cpr.2014.11.003

Puff, J., \& Renk, K. (2014). Relationships among parents’ economic stress, parenting, and young children's behavior problems. Child Psychiatry \& Human Development, 45(6), 712-727. doi:10.1007/s10578-014-0440-z 
Rajmil, L., Herdman, M., Ravens-Sieberer, U., Erhart, M., \& Alonso, J. (2014).

Socioeconomic inequalities in mental health and health-related quality of life (HRQOL) in children and adolescents from 11 European countries. International Journal of Public Health, 59(1), 95-105. doi:10.1007/s00038-013-0479-9

Ranta, J., \& Raitasalo, K. (2015). Disorders of cognitive and emotional development in children of mothers with substance abuse and psychiatric disorders. Nordic Studies on Alcohol and Drugs, 32(6), 591-604. doi:10.1515/nsad-2015-0056

Redelinghuys, J., \& Dar, K. (2008). A survey of parents receiving treatment for substance dependence: The impact on their children. Journal of Substance Use, 13, 37-48. doi:10.1080/14659890701538786

Reedtz, C., Lauritzen, C., \& van Doesum, K. T. M. (2012). Evaluating workforce developments to support children of mentally ill parents: Implementing new interventions in the adult mental healthcare in Northern Norway. BMJ Open, 2(3): e000709. doi:10.1136/bmjopen-2011-000709

Reiss, F. (2013). Socioeconomic inequalities and mental health problems in children and adolescents: A systematic review. Social Science \& Medicine, 90, 24-31. doi:10.1016/j.socscimed.2013.04.026

Rescorla, L. A., Ginzburg, S., Achenbach, T. M., Ivanova, M. Y., Almqvist, F., Begovac, I., ... \& Döpfner, M. (2013). Cross-informant agreement between parent-reported and adolescent self-reported problems in 25 societies. Journal of Clinical Child \& Adolescent Psychology, 42(2), 262-273. doi:10.1080/15374416.2012.717870

Ridenour, T. A., Tarter, R. E., Reynolds, M., Mezzich, A., Kirisci, L., \& Vanyukov, M. (2009). Neurobehavior disinhibition, parental substance use disorder, neighborhood quality and development of cannabis use disorder in boys. Drug and Alcohol Dependence, 102, 71-77. doi:10.1016/j.drugalcdep.2009.01.009

Robertson, A. A., Baird-Thomas, C., \& Stein, J. A. (2008). Child victimization and parental monitoring as mediators of youth problem behaviors. Criminal Justice and Behavior, 35, 755-771. doi:10.1177/0093854808316096

Santiago, C. D., Kaltman, S., \& Miranda, J. (2013). Poverty and mental health: How do lowincome adults and children fare in psychotherapy? Journal of Clinical Psychology, 69(2), 115-126. doi:10.1002/jclp.21951

Sayal, K., Heron, J., Golding, J., Alati, R., Smith, G. D., Gray, R., \& Emond, A. (2009). Binge pattern of alcohol consumption during pregnancy and childhood mental health outcomes: Longitudinal population-based study. Pediatrics, 123, 289-296. doi:10.1542/peds.2008-1861 
Schuetze, P., \& Eiden, R. D. (2006). The association between maternal cocaine use during pregnancy and physiological regulation in 4- to 8-week-old infants: An examination of possible mediators and moderators. Journal of Pediatric Psychology, 31(1), 15-26. doi:10.1093/jpepsy/jsj022

Shahrbabaki, M. E., Ziaaddini, H., Gargari, H. S., Nakhaee, N., Shahrbabaki, P. E., \& Sharbabaki, N. E. (2010). Comparison of internalizing disorders in 8-14-year-old offspring of opium and heroin dependent parents: A case-control study. Addiction \& Health, 2, 42-47.

Sollie, H., Larsson, B., \& Mørch, W. T. (2012). Comparison of mother, father, and teacher reports of ADHD core symptoms in a sample of child psychiatric outpatients. Journal of Attention Disorders, 17(8),699-710. doi:10.1177/1087054711436010

Steinhausen, H. C., Dal Mas, S., Ledermann, C., \& Metzke, C. W. (2006). Risk factors for the development of emotional and behavioural problems in children born to drugdependent mothers. European Child \& Adolescent Psychiatry, 15, 460-466. doi:10.1007/s00787-006-0568-x

Stone, L. L., Janssens, J. M., Vermulst, A. A., Van Der Maten, M., Engels, R. C., \& Otten, R. (2015). The Strengths and Difficulties Questionnaire: Psychometric properties of the parent and teacher version in children aged 4-7. BMC Psychology, 3(1), 4. doi:10.1186/s40359-015-0061-8

Stringer, K. L., \& Baker, E. H. (2015). Stigma as a barrier to substance abuse treatment among those with unmet need: An analysis of parenthood and marital status. Journal of Family Issues. Advance online publication. doi:10.1177/0192513X15581659

VanDeMark, N. R., Russell, L. A., O’Keefe, M., Finkelstein, N., Noether, C. D., \& Gampel, J.C. (2005). Children of mothers with histories of substance abuse, mental illness, and trauma. Journal of Community Psychology, 33, 445-459. doi:10.1002/jcop.20062

van den Einde-Bus, A. E. M., Goldschmeding, J. E. J., Tielen, L. M., de Waart, F. G., \& van de Looij-Jansen, P. M. (2010). Jongeren die opgroeien met een langdurig ziek, gehandicapt of verslaafd familielid: reden tot zorg [Young people who grow up with a long-term sick, disabled or addicted relative: Causes of concern]. Tijdschrift voor Gezondheidswetenschappen [Health Sciences Journal] 88, 79-88. doi:10.1007/BF03089553

Vanderplasschen, W., Autrique, A., \& De Wilde, J. (2010). Drugverslaafde ouders [Drug addicted parents]. Gezin [Family], 6, 208-227.

van der Zanden, R. A., Speetjens, P. A., Arntz, K. S., \& Onrust, S. A. (2010). Online group course for parents with mental illness: Development and pilot study. Journal of Medical Internet Research, 12 (5), 1-13. doi:10.2196/jmir.1394 
van Lier, P. A., \& Koot, H. M. (2010). Developmental cascades of peer relations and symptoms of externalizing and internalizing problems from kindergarten to fourth-grade elementary school. Development and Psychopathology, 22(3), 569-582. doi:10.1017/S0954579410000283

van Santvoort, F., Hosman, C. M. H., van Doesum, K. T. M., \& Janssens, J. M. (2013). Children of mentally ill or addicted parents participating in preventive support groups. International Journal of Mental Health Promotion, 15, 198-213. doi:10.1080/14623730.2013.851816

van Santvoort, F., Hosman, C. M. H., van Doesum, K. T. M., \& Janssens, J. M. (2014). Effectiveness of preventive support groups for children of mentally ill or addicted parents: arandomized controlled trial. European Child \& Adolescent Psychiatry, 23, 473-484. doi:10.1007/s00787-013-0476-9

van Widenfelt, B. M., Goedhart, A. W., Treffers, P. D., \& Goodman, R. (2003). Dutch version of the Strengths and Difficulties Questionnaire. European Child \& Adolescent Psychiatry, 12, 281-289. doi:10.1007/s00787-003-0341-3

Vitaro, F., Wanner, B., Brendgen, M., \& Tremblay, R. E. (2008). Offspring of parents with gambling problems: Adjustment problems and explanatory mechanisms. Journal of Gambling Studies, 24, 535-553. doi:10.1007/s10899-008-9096-6

Vogels, A. G., Crone, M. R., Hoekstra, F., \& Reijneveld, S. A. (2009). Comparing three short questionnaires to detect psychosocial dysfunction among primary school children: A randomized method. BMC Public Health, 9, 489. doi:10.1186/1471-2458-9-489

Vucinovic, M., Roje, D., Vučnović, Z., Capkun, V., Bucat, M., \& Banović, I. (2008). Maternal and neonatal effects of substance abuse during pregnancy: Our ten-year experience. Yonsei Medical Journal, 49, 705-713. doi:10.3349/ymj.2008.49.5.705

Wansink, H. J., Janssens, J. M., Hoencamp, E., Middelkoop, B. J., \& Hosman, C. M. H. (2015). Effects of preventive family service coordination for parents with mental illnesses and their children, a RCT. Families, Systems, \& Health, 33, 110-119. doi:10.1037/fsh0000105

Yang, S., \& Kramer, M. S. (2012). Paternal alcohol consumption, family transition and child development in a former Soviet country. International Journal of Epidemiology, 41, 1086-1096. doi:10.1093/ije/dys071 